\title{
What are the Gaps in Mobile Patient Portal? Mining Users Feedback using Topic Modeling
}

\author{
Cherie Noteboom \\ Dakota State University \\ Cherie.Noteboom@dsu.edu
}

\author{
Mohammad A. Al-Ramahi \\ Indiana University East \\ moaabdel@iu.edu
}

\begin{abstract}
Patient portals are positioned as a central component of patient engagement through the potential to change the physician-patient relationship and enable chronic disease self-management. In this article, we extend the existing literature by discovering design gaps for patient portals from a systematic analysis of negative users' feedback from the actual use of patient portals. Specifically, we adopt topic modeling approach, LDA algorithm, to discover design gaps from online low rating user reviews of a common mobile patient portal, EPIC's mychart. To validate the extracted gaps, we compared the results of LDA analysis with that of human analysis. Overall, the results revealed opportunities to improve collaboration and to enhance the design of portals intended for patientcentered care.
\end{abstract}

\section{Introduction}

According to Clifton [1], healthcare in America costs 2.5 trillion a year and is expected to grow to 4.5 trillion in six years. According to the Agency for Healthcare Quality and Research, automation is able to improve the quality and safety of care delivered by healthcare facilities by enabling collaboration among physicians, medical personnel and patients. Understanding the healthcare context is key to understanding the integration of IS (Information Systems) into the fabric of their organizations. According to Fichman, et al. [2], "at the most general level, a striking feature of healthcare industry is the level of diversity that characterizes patients (e.g. physical traits, and medical history), professional disciplines (e.g. doctors, nurses, administrators and insurers), treatment options, healthcare delivery processes and interests of various stakeholder groups".
In this regard, patient-centered care is seen to be a natural progression towards greater efficiency and effectiveness in healthcare provision. This form of care is one in which a patient actively participates in his or her care, delivery of care takes place from a patient's point of view, there is greater communication with the patient and therapy is tailored to the needs of the patient [3-5]. The implementation of Health Information Technology (HIT) appears to have enabled greater patientcentered care through better access to patient data, shorter recovery through targeted care, lower cost through fewer tests [3, 6-8].

Patient-centered care implies a paradigm shift in the relationship between doctors and patients, but also requires the development of self-management practices [4]. Kane and Labianca [9] note that "If patients fail to manage their chronic diseases adequately, escalating conditions can become extremely expensive to treat and can significantly compromise the patient's quality of life". To help patients self-manage their diseases, information made available from HIT products such as home health devices and patient portals. Patient Health Records (PHR) technology, often known as patient portal, provides patients with online access to their health records which in turn enables better disease management through tracking of comprehensive health indicators and lower the cost of care $[6,7]$. Through the potential to provide continuity of service and better care, and the potential to change the physician-patient relationship and enable chronic disease self-management, patient portals are positioned as a central component of patient engagement [10].

Previous technology research [e.g., 11, 12, 13] has investigated collaboration effects and provides insight to inform the patient portal research in the areas of collaboration, coordination, communication and adaptation. In addition, the adaptation insights at 
the work, social, and technology levels inform this research. However, up to now, very few efforts have been made to extract knowledge from online user reviews from actual use of mobile patient portals to help understand patients' concerns that deter effective use of these health technology. Therefore, this research answers the call for the development of patient-oriented research by investigating the key challenges relating to the use of mobile patient portals (i.e., determining the gaps in the design of patient portals) via extracting insights from negative users' reviews of patient portal mobile apps. Such insights can improve the partnership and collaboration between patients and healthcare providers.

The advances of Web 2.0 technologies have enabled consumers to easily and freely exchange opinions on products and services on an unprecedented scale (volume) and in real time (velocity). Online user review systems provide us with one of the most powerful channels for extracting user feedback that can help enhance patient portals design. In the e-commerce domain, user reviews have long been widely recognized as a crucial factor that influences product sales [e.g., 14] and shapes consumers' purchase intention [e.g., 15]. In the domain of patient portal systems, analyzing users' reviews has the potential to greatly inform developers of patients' preferences and how they engage with health portals and provide opportunities for further enhancing their efficacy.

In this study, we systematically analyze users' reviews to identify design gaps from the actual use of mobile patient portal. The question investigated in this paper is: what are the gaps in mobile patient portal service to enable patient-centered care? To answer this question, we use an implementation of EPIC's mychart as an instance of mobile patient portal and discover design gaps based on a systematic analysis of users' negative reviews. Instead of manually analysing the data, which is time consuming, we utilize a text-mining technique, specifically topic modeling, to analyze the contents of user reviews and identify design gaps for mobile patient portal systems. The key contribution of this research is in discovering the gaps that may exist in current mobile patient portal solutions and identifying the opportunities for mobile patient portal enhancement to achieve improved patient-centered care.

\section{Related Work \& Background}

\subsection{Patient-Centered Care}

Effective patient-centered care centers on the identification of the best intervention for every individual patient using personalized medicine and tailored therapeutics [4]. To provide patient-centered care, physicians will have to collaborate. Collaboration is a purposeful joint action through the construction of relevant meanings that are shared among members. Collaboration is needed to: 1) determine what action is required and relevant; 2) identify knowledge to carry out a required action; 3) demand for action. In order to support collaboration, it is necessary to have a media with which to communicate and a social network or "community of minds."

In this regard, patient portals have the potential to better inform and engage patients in their care. Patient portals, now commonly used in ambulatory settings, leverage integration with electronic health record (EHR) efforts to inform and engage patients. Healthcare providers feel the information provided by the portal helps facilitate patient engagement in care and identification of errors [16].

\subsection{Patient Health Records (Patient Portal)}

With the exponential growth of the communications technologies that allow us to potentially reach more individuals regardless of their locations, new types of health intervention emerged. Smartphone or mobile-based patient portals can enhance patients' engagement at a very low cost. Due to the promising influence of these smartphone-based technologies in supporting healthy lifestyle and selfcare practices, researchers have been inspired to explore the impact and use of mobile applications. For example, the fact that women widely used mobile apps for health information during pregnancy, but reported apps as unavailable or invaluable postpartum, highlights the need for the development of more mobile apps with postpartum content [17]. With this respect, Zhang, et al. [18]'s study is one of the first few studies to describe the methodology of developing an online and smartphone compatible cognitive behavioral therapy intervention program for bariatric surgery patients.

While the results of HIT use by providers are mixed, it appears that motivated patients can achieve significant improvements in their health outcomes when they use mobile applications [19]. There are currently over 3000 mobile applications available through Google Playstore and Apple Store to support lifestyle changes such as fitness, calorie counter and Body Mass Index calculators some of which are used to control diabetes[19, 20]. 
Little research, however, has been done to connect the growing mobile application use by patients to accessing their healthcare data. From a public health perspective, patient-centered care requires "a partnership among practitioners, patients, and their families (when appropriate) to ensure that decisions respect patient's wants, needs, and preferences and that patients have the education and support they need to make decisions and participate in their own care" [21]. Robinson, et al. [22] also offer an economic view of the patient as the informed consumer who makes decisions based on cost and quality of care. They also identify care from a patient's perspective to include 'respect, courtesy, competence, efficiency, patient involvement in decisions, time for care, availability/accessibility, information, exploring patient's needs, and communication" [22]. In order to address these views, patient health portals will need to be customized for patient-centered care.

The focus of previous studies included providing access to the patient record and information on the care team through a mobile phone app [e.g., 23], a tablet computer app to view care team profiles and hospital medication records, and a tablet app with the plan of care, diet and safety information [24]. Providing patients real-time access to health information has been demonstrated as a positive force for change in the way care is provided [10]. In this regard, Lu, et al. [25] develop an App to inspect controlled substances in patient care units. Using a web-enabled smartphone, pharmacist inspection can be performed on site and the inspection results can be directly recorded into the HIS through the Internet so human error of data translation can be minimized and the work efficiency and data processing can be improved.

While previous studies reported positive findings, including patient reports of enhanced engagement in the care process and satisfaction with care, none included patient-centered functionality such as the ability to send messages to the care team, allowing patients to input information or record noteselements that have been demonstrated to further enhance patients' engagement [10]. This is especially true with the proliferation of wearable devices, where data about an individual's health state can be collected by real-time sampling and analysis of a few parameters using noninvasive, inexpensive, and portable devices [26]. With this respect, Neubeck, et al. [27]) adopted a collaborative user-centered design process to develop a patient-centered care tool. O'Leary, et al. [16] concluded that optimizing a hospital-based patient portal will require attention to type, timing and format of information provided, as well as the impact on patient-provider communication and workflow. Patients can identify areas of improvement that could enhance the design of portals. For example, patients suggested inclusion of a test result feature [16]. Therefore, further research is needed to work in concert with patients to explore patient-centered functionalities that help develop a patient-centric portal to increase patients' engagement in their care.

Leveraging user feedback from the actual use of mobile patient portal, this research contributes to an understanding of how the technology architecture can enable patients to interact with patient portal functionality, which is technological adaptation, to work (work adaptation) together with their physicians and care providers (social adaptation) using the content available to them and using the collaboration media to provide patient-centered care.

\subsection{The Impacts of User-Generated Content}

Several researchers in the areas of social media and e-commerce have studied the effects of usergenerated content such as online users' reviews and rating systems on product sales and consumers' purchase intention. The findings of the existing research have demonstrated that analyzing and measuring these electronic word-of-mouth (eWOM) messages is quite valuable in product design, sales prediction, marketing strategy, and other decisionmaking tasks [e.g., 28, 29, 30]. In this regard, Guo, et al. [31] adopted Latent Dirichlet Allocation (LDA) as topic modeling technique to discover key dimensions from online user reviews for hotels located in 16 countries.

Recently, few researchers have been attracted to explore the impact of user-generated content in healthcare domain. For example, Jung, et al. [32] proposed a text mining approach to identify hospital service quality factors and overtime trends automatically from user-generated content from online health communities. Xu, et al. [33] examined the impact of online information on patient choice of outpatient care doctors. Al-Ramahi, et al. [34], [35] use topic modeling, LDA algorithm, to discover design principles for Health Behavioral Change Support Systems (HBCSSs) from online user reviews of mobile diabetes applications. However, to best of our knowledge, no research to date has looked at online users reviews in the context of mobile patient portals. User reviews implicitly communicate satisfaction/dissatisfaction based on actual usage experience and may provide a good opportunity for extracting design dimensions that can strongly 
influence users' satisfaction and then informing the design of these systems.

\section{Method}

This section describes the methodology used to investigate what are the gaps in mobile patient portal service to enable patient-centered care? Fig 1. shows the framework of the text mining-based method, which is adopted from [34]. We propose to use an unsupervised topic model, Latent Dirichlet Allocation (LDA), to extract latent dimensions (i.e. design gaps) from user-generated data. Below, we first discuss the data collection and preparation process. We then explain the topic modeling technique used to extract design gaps from online low ratings users' reviews.

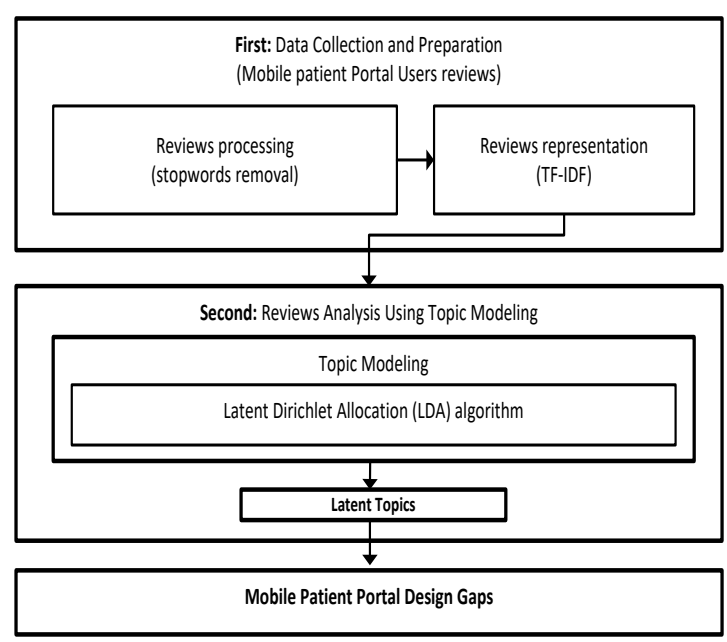

Figure 1. Architecture of our text mining-based method [34].

\subsection{Data Collection and Preparation}

In this study, our target population is mobile patient portal users. The patient portal selected as empirical setting of this research is EPIC's mychart. We selected this patient portal for study as Epic is replacing other vendors in the EHR market and is beginning to establish a single vendor landscape. Reportedly, Epic has at least partial health information for over $51 \%$ of the US population [36]. MyChart mobile app is available for Apple and Android devices. The data was collected from Apple iTunes store, where the online reviews posted by the users were gathered using the Apple store API. We developed a web crawler to automatically collect data. Through this process, we obtain our data set consisting of 500 reviews. Since the main objective of this research is to identify design gaps of mobile patient portal, we focused on users' complaints contained in 1- or 2-star reviews. In comparison with the high-rated reviews, these low-rated reviews are more likely to reflect users' concerns and shed light on gaps that should be considered but unfortunately have been ignored in the current research and practice. In total, we analyzed 258 1- and 2-star reviews. When preprocessing the data, we removed stop words and represented each document using the well-known Term Frequency Inverse Document Frequency (TF-IDF) weighting scheme [37]. To adopt this weighting scheme, we treat each user review in the data set as a document. Specifically, TF-IDF weight of a word $i$ in a user review $j$ is given by

$$
F_{i_{i} j} * \log (N / D F)
$$

Where $F_{i, j}$ is the frequency of the word $i$ in the user review $j, \mathrm{~N}$ indicates the number of user reviews in the corpus, and DF is the number of user reviews that contains word $i$.

\subsection{Topic Modeling: LDA}

Topic models are statistical-based algorithms for discovering the main themes (i.e. set of topics) that describe a large and unstructured collection of documents. Topic models allow us to summarize textual data at a scale that is impossible to be tackled by human annotation. We selected the Latent Dirichlet Allocation (LDA) model, the most common topic model currently in use, due to its conceptual advantage over other latent topic models [38]. The model generates automatic summaries of topics in terms of a discrete probability distribution over words for each topic, and it also infers per-document discrete distributions over topics. The interaction between the observed documents and hidden topic structure is manifested in the probabilistic generative process associated with LDA. This generative process can be thought of as a random process that is assumed to have produced the observed document [39]. To illustrate the results of LDA, Let $M, K, N$, and $V$ be the number of documents in a collection, the number of topics, the number of words in a document, and the vocabulary size, respectively. The first result is an $M \times K$ matrix, where the weight $w_{m, k}$ is the association between a document $d_{m}$ and a topic $t_{k}$. In our case, the documents are user reviews for patient portal mychart app (i.e. we integrated the 
reviews of the app in a data file and treated each user review as a single document) $(M=258)$. The second result is an $N \times K$ matrix, where the weight $w_{n, k}$ is the association between a word $w_{n}$ and a topic $t_{k}$. The notations Dirichlet(.) and Multinomial(·) represent Dirichlet and multinomial distribution with parameter (·) respectively. The graphical representation of LDA is shown in Fig. 2, and the corresponding generative process is shown below:

(1) For each topic $\mathrm{t} \in\{1, \ldots, K\}$,

(a) draw a distribution over vocabulary words $\beta_{t} \sim \operatorname{Dirichlet}(\eta)$.

(2) For each document d,

(a) draw a vector of topic proportions $\theta_{d} \sim \operatorname{Dirichlet}(\alpha)$.

(b) For each word $w_{n}$ in document d, where $n \in\{1, \ldots, N\}$,

(i) draw a topic assignment $\mathrm{z}_{\mathrm{n}} \sim \operatorname{Multinomial}\left(\theta_{\mathrm{d}}\right)$

(ii) draw a word $w_{n} \sim \operatorname{Multinomial}\left(\beta_{\mathrm{z} n}\right)$.

The notation $\beta_{t}$ is the $V$-dimensional word distribution for topic $t$, and $\theta_{d}$ is the $K$-dimensional topic proportion for document $d$. The notations $\eta$ and $\alpha$ represent the hyperparameters of the corresponding Dirichlet distributions.

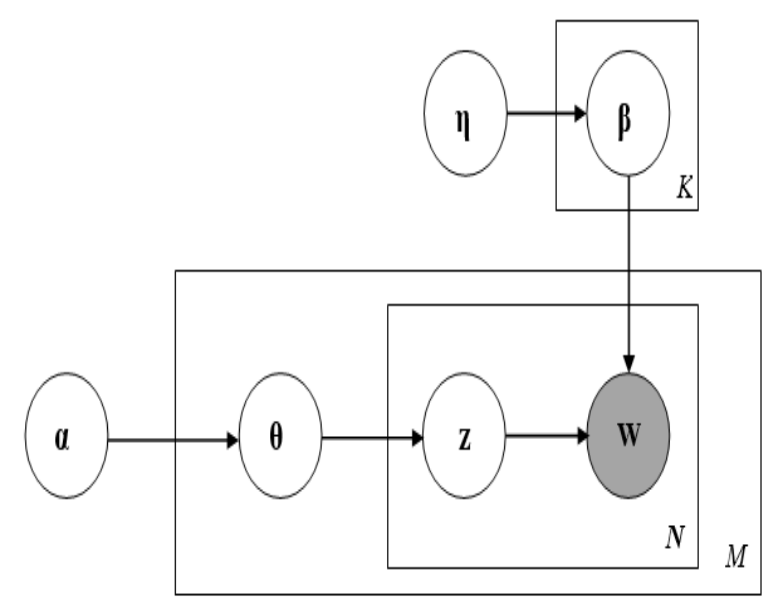

Figure 2. Graphical model of LDA

\section{Results}

\subsection{Gaps Discovered}

In this section, we summarize and discuss the results of the extraction of the topics of the users' negative experience (i.e., gaps of mobile patient portal). We apply LDA to extract and label the topics of users' concerns across all collected low rating reviews of mychart portal in our sample. The LDA identified 25 topics and within each topic showed the top-10 words and their relative weight (i.e. probability). The naming of topics was first conducted by the first author and confirmed by the second author. Naming was initially based on the identification of a logical connection between these 10 most frequent words for a topic. For example, in Table 1, the topic name "Way to update and schedule appointment" is based on the word 'Appointments', weighted $1.3 \%$, 'update' weighted $0.9 \%$, and 'Schedule', weighted $0.7 \%$, both of which appear at the top 10 words. Once specified, a candidate topic label was then further tested via investigating the reviews that are highly associated with that topic.

Table 1: Examples of identifying topics labels

\begin{tabular}{|c|c|c|c|}
\hline Topic & $\begin{array}{l}\text { Weight } \\
(\%)\end{array}$ & Topic & $\begin{array}{l}\text { Weight } \\
(\%)\end{array}$ \\
\hline \multicolumn{2}{|c|}{$\begin{array}{l}\text { Topicl: Way to update and } \\
\text { schedule appointment }\end{array}$} & $\begin{array}{l}\text { Topic 2: } \\
\text { touch ID }\end{array}$ & $g$ in using \\
\hline needs & $1.5 \%$ & ipad & $1.0 \%$ \\
\hline appointments & $1.3 \%$ & beneficial & $0.9 \%$ \\
\hline app & $1 \%$ & available & $0.8 \%$ \\
\hline info & $0.9 \%$ & $\log$ & $0.8 \%$ \\
\hline update & $0.9 \%$ & id & $0.8 \%$ \\
\hline updated & $0.8 \%$ & app & $0.8 \%$ \\
\hline way & $0.7 \%$ & touch & $0.8 \%$ \\
\hline unable & $0.7 \%$ & alert & $0.8 \%$ \\
\hline schedule & $0.7 \%$ & longer & $0.7 \%$ \\
\hline ability & $0.7 \%$ & topic & $0.7 \%$ \\
\hline
\end{tabular}

The topics obtained were then mapped into 10 design gaps shown in Table 2 along with examples from user feedback. The mappings between the topics and the gaps were sometimes one-to-one. For instance, the topic "notifications" was mapped to the gap "Notifications/alerts" and the topic "information summaries" to the gap "Informative presentation". There are also some gaps that correspond to multiple topics. For example, the Appointments related topics; "way to update and schedule appointment", "Print appointments", "track appointments with providers", and "update appointment" were mapped into the gap "Appointments management".

Table 2: Gaps identified supported by examples from user feedback

\begin{tabular}{|l|l|}
\hline \multicolumn{1}{|c|}{ Gap } & $\begin{array}{l}\text { Examples from the user } \\
\text { feedback }\end{array}$ \\
\hline $\begin{array}{l}\text { Gap 1: Appointments } \\
\text { management: This gap } \\
\text { refers to patients' inability } \\
\text { to manage their } \\
\text { appointments over the }\end{array}$ & $\begin{array}{l}\text { - can't even schedule or } \\
\text { request an appt with it } \\
\text { - just downloaded the app } \\
\text { but could not schedule } \\
\text { appointments on iPhone or }\end{array}$ \\
\hline
\end{tabular}




\begin{tabular}{|c|c|}
\hline $\begin{array}{l}\text { portal. For examples, they } \\
\text { cannot request, schedule, } \\
\text { print, track appointments } \\
\text { and cannot even view their } \\
\text { appointment schedule in an } \\
\text { appropriate format. }\end{array}$ & $\begin{array}{l}\text { iPad } \\
\text { - you no longer can read } \\
\text { your appointment schedule } \\
\text { or any information in a } \\
\text { normal sentence } \\
\text { - appointment layout } \\
\text { horrible }\end{array}$ \\
\hline $\begin{array}{l}\text { Gap 2: Notifications/alerts: } \\
\text { This gap pertains to the lack } \\
\text { of providing patients with } \\
\text { notifications/alerts when a } \\
\text { doctor has a new results or } \\
\text { message for them or when } \\
\text { they have an upcoming } \\
\text { appointment. }\end{array}$ & $\begin{array}{l}\text { - needs notifications/alerts. } \\
\text { Useless if not notified of } \\
\text { the important messages } \\
\text { received within the app. } \\
\text { Unable to find any way to } \\
\text { enable notifications } \\
\text { - please add an email alert } \\
\text { option! } \\
\text { - I can't even get new } \\
\text { notifications when my } \\
\text { doctor has a new results or } \\
\text { a message for me } \\
\text { - I can't believe that there } \\
\text { has been another update } \\
\text { and still no push } \\
\text { notifications! }\end{array}$ \\
\hline $\begin{array}{l}\text { Gap 3: Integration with } \\
\text { other health apps: This gap } \\
\text { relates to not having the } \\
\text { portal (Mychart) integrated } \\
\text { with other health apps (like } \\
\text { FitBit and Apple HealthKit) } \\
\text { so that patients can } \\
\text { synchronize their health } \\
\text { data both ways, from } \\
\text { Mychart to health apps (like } \\
\text { lab results) and from health } \\
\text { apps to Mychart. }\end{array}$ & $\begin{array}{l}\text { - no sync with Apple } \\
\text { Health } \\
\text { - the MyChart app should } \\
\text { integrate with Health on } \\
\text { iOS. Ideally, lab results } \\
\text { would be sourced from } \\
\text { MyChart and feed into } \\
\text { Apple's Health. iOS Health } \\
\text { data should be read by } \\
\text { MyChart and placed in to a } \\
\text { message or a report for my } \\
\text { physician. }\end{array}$ \\
\hline $\begin{array}{l}\text { Gap 4: Communication } \\
\text { with health providers: This } \\
\text { gap refers to patients' } \\
\text { inability to communicate } \\
\text { well with their health } \\
\text { providers via the portal. In } \\
\text { this regard, patients neither } \\
\text { can exchange messages } \\
\text { with health providers nor } \\
\text { send them their test results. }\end{array}$ & $\begin{array}{l}\text { - this app doesn't give you } \\
\text { the option to reply when } \\
\text { you get a msg from your } \\
\text { doctor. You have to send a } \\
\text { new msg } \\
\text { - no way to send test results } \\
\text { to doctors } \\
\text { - I cannot send my doctor } \\
\text { any messages } \\
\text { - actually makes } \\
\text { communicating with your } \\
\text { doctor harder } \\
\text { - need to add the feature of } \\
\text { getting messages from } \\
\text { doctors } \\
\text { - I want to read sent emails. }\end{array}$ \\
\hline $\begin{array}{l}\text { Gap 5: Security issues: This } \\
\text { gap refers to the absence of } \\
\text { "Touch ID" feature that } \\
\text { allows patients to log in } \\
\text { using their fingerprint and } \\
\text { patients' inability to } \\
\text { manage their password. }\end{array}$ & $\begin{array}{l}\text { - why isn't Touch ID } \\
\text { available. } \\
\text { - I would really like Touch } \\
\text { ID support for logging into } \\
\text { my provider instead of } \\
\text { entering my password } \\
\text { every time } \\
\text { - It also lacks integration } \\
\text { with popular password } \\
\text { managers such as }\end{array}$ \\
\hline
\end{tabular}

\begin{tabular}{|c|c|}
\hline & $\begin{array}{l}\text { 1Password } \\
\text { - For many of us who have } \\
\text { multiple changing } \\
\text { passwords this app is a } \\
\text { nightmare }\end{array}$ \\
\hline $\begin{array}{l}\text { Gap 6: Access and retrieve } \\
\text { data: This gap refers to } \\
\text { patients' inability to access } \\
\text { and retrieve health related } \\
\text { data like diagnostic or } \\
\text { bloodwork info, weight, bp, } \\
\text { medical tests or history. }\end{array}$ & $\begin{array}{l}\text { - I have several health data } \\
\text { about my sleep, exercises } \\
\text { and some more that my } \\
\text { doctor would love to have } \\
\text { access to } \\
\text { - can't access any of my } \\
\text { diagnostic or bloodwork } \\
\text { info } \\
\text { - cannot access my weight, } \\
\text { bp, etc record } \\
\text { - cannot access to any of } \\
\text { the medical tests or history } \\
\text { - miss a lot of information } \\
\text { especially in the health } \\
\text { summary it's not an exact } \\
\text { copy of your medical } \\
\text { records } \\
\text { - cannot retrieve any data } \\
\text { since most recent update }\end{array}$ \\
\hline $\begin{array}{l}\text { Gap 7: Informative } \\
\text { presentation (data to } \\
\text { knowledge presentation): } \\
\text { This gap refers to patients' } \\
\text { inability to track their health } \\
\text { with graphs/charts and } \\
\text { inability to display their } \\
\text { health data at multiple } \\
\text { levels of aggregations, } \\
\text { "drill-down" and "roll-up", } \\
\text { on Dashboard. }\end{array}$ & $\begin{array}{l}\text { - no ability to track health } \\
\text { with graphs; charts, } \\
\text { - instead of displaying data } \\
\text { on Dashboard in } \\
\text { discussions with doctors. I } \\
\text { have to manually download } \\
\text { data to a spreadsheet -- } \\
\text { unneeded waste of effort } \\
\text { - also, the Health Summary: } \\
\text { Heath Issues; section is a } \\
\text { weird subset of random one } \\
\text { liners, none of which are } \\
\text { clickable to get more } \\
\text { information. I wish it was } \\
\text { much more complete with } \\
\text { all the notes my doctors } \\
\text { have written. }\end{array}$ \\
\hline $\begin{array}{l}\text { Gap 8: Update medical } \\
\text { data: This gap refers to } \\
\text { patients' inability to } \\
\text { update/correct/upload } \\
\text { medical data like blood } \\
\text { pressure. }\end{array}$ & $\begin{array}{l}\text { - upload updated insurance } \\
\text { cards and be able to } \\
\text { indicate which one is the } \\
\text { primary and which one is } \\
\text { the } 2 \text { nd one } \\
\text { - it be great if I could } \\
\text { update my shots and other } \\
\text { medical issues } \\
\text { - gives no ability to } \\
\text { patient/user to } \\
\text { correct/update data. Have to } \\
\text { request medical personnel } \\
\text { to make changes } \\
\text { - should be able to upload } \\
\text { common health metrics like } \\
\text { blood pressure } \\
\text { - add support to upload pdf } \\
\text { files }\end{array}$ \\
\hline $\begin{array}{l}\text { Gap 9: Install/open the app: } \\
\text { This gap refers to patients' }\end{array}$ & $\begin{array}{l}\text { - haven't been able to open } \\
\text { the app for weeks now! }\end{array}$ \\
\hline
\end{tabular}




\begin{tabular}{|l|l|}
\hline $\begin{array}{l}\text { inability to install and open } \\
\text { the app. }\end{array}$ & $\begin{array}{l}\text { - I can't open or use this } \\
\text { app } \\
\text { - problems downloading } \\
\text { and installing! } \\
\text { - cannot install on iPhone 7 } \\
\text { plus }\end{array}$ \\
\hline $\begin{array}{l}\text { Gap 10: Communicating } \\
\text { with server problems: } \text { This } \\
\text { gap refers to patients } \\
\text { inability to connect to the } \\
\text { server sometimes. }\end{array}$ & $\begin{array}{l}\text { - keeps saying cannot } \\
\text { connect to server } \\
\text { - down more than a week. } \\
\text { Can't communicate with } \\
\text { the server } \\
\text { - will not let me sign in to } \\
\text { my chart from Cleveland } \\
\text { clinic and it keeps saying } \\
\text { Problem communicating } \\
\text { with the server }\end{array}$ \\
\hline
\end{tabular}

\subsection{Validity of Gaps Discovered}

We examined the validity of the extracted gaps by comparing the results of LDA analysis with that of human analysis (see Table 3 ). To conduct the manual analysis, we adopted open coding technique for data analysis. Two independent researchers read the collected 1- and 2-star reviews and then identify the gaps mentioned in these reviews. We compared the gaps derived from the LDA analysis with the ones identified by the two researchers to calculate the reliability of the LDA result. The Jaccard coefficient ${ }^{1}$ is 0.71 and 0.6 between the automated analysis and the two researchers, $\mathrm{A}$ and $\mathrm{B}$ respectively. As shown in Table 3, the manual coding of the data revealed four new gaps: "Export/Import data" that refers to the inability to export and save health data to files, "Support multiple health providers", "Technical support" and "Billing issues".

Table 3: A comparison of gaps between LDA analysis and human analysis

\begin{tabular}{|l|c|c|c|}
\hline Gap & $\begin{array}{l}\text { LDA } \\
\text { analysis }\end{array}$ & $\begin{array}{l}\text { Researc- } \\
\text { her A }\end{array}$ & $\begin{array}{l}\text { Researc- } \\
\text { her B }\end{array}$ \\
\hline $\begin{array}{l}\text { Appointments } \\
\text { management }\end{array}$ & $\sqrt{ }$ & $\checkmark$ & $\checkmark$ \\
\hline $\begin{array}{l}\text { Notifications } \\
\text { /alerts }\end{array}$ & $\sqrt{ }$ & $\checkmark$ & $\checkmark$ \\
\hline $\begin{array}{l}\text { Integration with } \\
\text { other health apps }\end{array}$ & $\checkmark$ & $\checkmark$ & $\checkmark$ \\
\hline $\begin{array}{l}\text { Communication } \\
\text { with health } \\
\text { providers }\end{array}$ & $\checkmark$ & $\checkmark$ & $\checkmark$ \\
\hline Security issues & $\checkmark$ & $\checkmark$ & $\checkmark$ \\
\hline $\begin{array}{l}\text { Access and } \\
\text { retrieve health }\end{array}$ & $\checkmark$ & $\checkmark$ & $\checkmark$ \\
\hline
\end{tabular}

1 The Jaccard coefficient measures similarity between finite sample sets, and is defined as the size of the intersection divided by the size of the union of the sample sets.

\begin{tabular}{|l|c|c|c|}
\hline data & & & \\
\hline $\begin{array}{l}\text { Informative } \\
\text { presentation } \\
\text { (data to } \\
\text { knowledge } \\
\text { presentation) }\end{array}$ & $\checkmark$ & $\checkmark$ & $\checkmark$ \\
\hline $\begin{array}{l}\text { Update medical } \\
\text { data }\end{array}$ & $\sqrt{ }$ & $\checkmark$ & $\mathrm{x}$ \\
\hline $\begin{array}{l}\text { Install/open the } \\
\text { app }\end{array}$ & $\checkmark$ & $\checkmark$ & $\mathrm{x}$ \\
\hline $\begin{array}{l}\text { Communicating } \\
\text { with server } \\
\text { problems }\end{array}$ & $\sqrt{ }$ & $\checkmark$ & $\checkmark$ \\
\hline $\begin{array}{l}\text { Export/Import } \\
\text { data }\end{array}$ & $\mathrm{X}$ & $\checkmark$ & $\checkmark$ \\
\hline $\begin{array}{l}\text { Support multiple } \\
\text { health providers }\end{array}$ & $\mathrm{x}$ & $\checkmark$ & $\mathrm{x}$ \\
\hline Technical support & $\mathrm{x}$ & $\checkmark$ & $\checkmark$ \\
\hline Billing issues & $\mathrm{x}$ & $\checkmark$ & $\checkmark$ \\
\hline
\end{tabular}

\section{Conclusions}

The rising cost and decreasing quality of health care has raised the impetus towards the use of patient portals and EHRs to overcome these issues with the increased transparency and increases in efficiency made possible by the technology. However, the challenges of patient portals have tempered efforts to improve efficiency of healthcare through the technology. This paper aims to investigate the gaps in mobile patient portal service to enable patientcentered care by analyzing the actual use of these systems. We adopt a text mining based approach to leveraging online user reviews as a primary data source. Given the market prominence of EPIC's mychart patient portal, we use it as a problem domain.

The results of this research identified opportunities for improvement from patients' perceptions. Several gaps emerged which reveal opportunities to enhance the design of portals intended for patient-centered care. These important findings can inform design decisions to promote use and foster engagement. Overall, optimizing a mobile patient portal will require careful attention to particular functionalities to enable collaboration like allowing patients to request and schedule an appointment "appointments management" and notifying them regarding new results and messages "Notifications/alerts". It is also paramount to enable patients to "communicate with health providers", "export/import" their health data, use their fingerprint to log in "security issues", and the portal should be "integrated with other health apps" (i.e., fitness apps). We found also that patients were interested to having the ability to update their health 
data like shots and common metrics like blood pressure as well as update insurance information (i.e., insurance cards).

Regarding the portal content, patients described the utility of "accessing and retrieving health data" such as test results, prescription, and patient's information like weight and blood pressure. This finding is consistent with research by O'Leary, et al. [16] demonstrating that hospitalized patients have a strong interest in all types of test results. It is also crucial that the portal provide patients with readable and informative graphs, reports, and charts of their health-related data, depicting their improvement patterns and historical trends "Informative presentation". To achieve better quality of care, the patient portals can provide the transparency needed as patients utilize the technology to support patient interaction and enable patients to access the information they need to make better decisions about their healthcare. These changes will positively influence patient-centered care.

Theoretically, this work contributes to the existing knowledge base of mobile patient portal design by 1) presenting some existing opportunities for design enhancements and 2) inferring new ones. Methodologically, this study exploits users' feedback in form of online reviews. In essence, the design of mobile patient portals require understanding of users' perceptions and concerns. In this regard, user involvement is key in portal systems design, which can help shift the focus of innovation from pure technology to the context of daily life [40]. Hence, we developed and presented opportunities for design enhancements based on users' reviews.

\section{References}

[1] J. Clifton, "Healthcare Is Killing Us," Gallup Business Journal, 2012.

[2] R. G. Fichman, R. Kohli, and R. Krishnan, "Editorial overview - the role of information systems in healthcare: current research and future trends," Information Systems Research, vol. 22, pp. 419-428, 2011.

[3] M. Stewart, J. Brown, A. Donner, I. McWhinney, J. Oates, W. W. Weston, et al., "The impact of patient-centered care on outcomes," Fam Pract, vol. 49, pp. 796-804, 2000.

[4] J. A. Sacristán, "Patient-centered medicine and patient-oriented research: improving health outcomes for individual patients," BMC medical informatics and decision making, vol. 13, p. 6, 2013.
[5] J. Murphy, "Patient as center of the health care universe: A closer look at patient-centered care," Nursing Economics, vol. 29, p. 35, 2011.

[6] S. B. Cohen, K. D. Grote, W. E. Pietraszek, and F. Laflamme, "Increasing consumerism in healthcare through intelligent information technology," The American journal of managed care, vol. 16, pp. SP37-43, 2010.

[7] B. Cliff, "Using Technology to Enhance Patient-Centered Care," Journal Of Healthcare Management, vol. 57, pp. 301-303, 2012.

[8] D. Blumenthal and M. Tavenner, "The "meaningful use" regulation for electronic health records," N Engl J Med, vol. 2010, pp. 501-504, 2010.

[9] G. C. Kane and G. Labianca, "IS avoidance in health-care groups: A multilevel investigation," Information Systems Research, vol. 22, pp. 504522, 2011.

[10] A. S. McAlearney, C. J. Sieck, J. L. Hefner, A. M. Aldrich, D. M. Walker, M. K. Rizer, et al., "High Touch and High Tech (HT2) Proposal: Transforming Patient Engagement Throughout the Continuum of Care by Engaging Patients with Portal Technology at the Bedside," JMIR Research Protocols, vol. 5, 2016.

[11] S. Qureshi and P. Keen, "Activating knowledge through electronic collaboration: Vanquishing the knowledge paradox," IEEE Transactions on Professional Communication, vol. 48, pp. 40-54, 2005.

[12] S. Qureshi, M. Liu, and D. Vogel, "A grounded theory analysis of e-collaboration effects for distributed project management," in System Sciences, 2005. HICSS'05. Proceedings of the 38th Annual Hawaii International Conference on, 2005, pp. 264c-264c.

[13] S. Qureshi and C. Noteboom, "Adaptation in distributed projects: Collaborative processes in digital natives and digital immigrants," in System Sciences, 2006. HICSS'06. Proceedings of the 39th Annual Hawaii International Conference on, 2006, pp. 202c-202c.

[14] J. A. Chevalier and D. Mayzlin, "The effect of word of mouth on sales: Online book reviews," Journal of marketing research, vol. 43, pp. 345354, 2006.

[15] J. Yang, R. Sarathy, and J. Lee, "The effect of product review balance and volume on online Shoppers' risk perception and purchase 
intention," Decision Support Systems, vol. 89, pp. 66-76, 2016.

[16] K. J. O’Leary, R. K. Sharma, A. Killarney, L. S. O'Hara, M. E. Lohman, E. Culver, et al., "Patients' and healthcare providers' perceptions of a mobile portal application for hospitalized patients," BMC Medical Informatics and Decision Making, vol. 16, p. 123, 2016.

[17] L. Guerra-Reyes, V. M. Christie, A. Prabhakar, A. L. Harris, and K. A. Siek, "Postpartum Health Information Seeking Using Mobile Phones: Experiences of Low-Income Mothers," Maternal and Child Health Journal, vol. 20, pp. 13-21, 2016.

[18] M. W. Zhang, R. Ho, S. E. Cassin, R. Hawa, and S. Sockalingam, "Online and smartphone based cognitive behavioral therapy for bariatric surgery patients: Initial pilot study," Technology and Health Care, vol. 23, pp. 737-744, 2015.

[19] J. M. García-Gómez, I. de la Torre-Díez, J. Vicente, M. Robles, M. López-Coronado, and J. J. Rodrigues, "Analysis of mobile health applications for a broad spectrum of consumers: a user experience approach," Health informatics journal, vol. 20, pp. 74-84, 2014.

[20] S. Qureshi, C. Noteboom, and A. M. Schumaker, "Mobile Access for Patient Centered Care: The Challenges of Activating Knowledge through Health Information Technology," in System Sciences (HICSS), 2015 48th Hawaii International Conference on, 2015, pp. 32273236.

[21] IOM, "Envisioning the national health care quality report," 2001.

[22] J. H. Robinson, L. C. Callister, J. A. Berry, and K. A. Dearing, "Patient-centered care and adherence: definitions and applications to improve outcomes," Journal of the American Academy of Nurse Practitioners, vol. 20, pp. 600607, 2008.

[23] L. Pfeifer Vardoulakis, A. Karlson, D. Morris, G. Smith, J. Gatewood, and D. Tan, "Using mobile phones to present medical information to hospital patients," in Proceedings of the SIGCHI Conference on Human Factors in Computing Systems, 2012, pp. 1411-1420.

[24] P. C. Dykes, D. L. Carroll, A. C. Hurley, A. Benoit, F. Chang, R. Pozzar, et al., "Building and testing a patient-centric electronic bedside communication center," Journal of gerontological nursing, 2012.
Y.-H. Lu, L.-Y. Lee, Y.-L. Chen, H.-I. Cheng, W.-T. Tsai, C.-C. Kuo, et al., "Developing an App by Exploiting Web-Based Mobile Technology to Inspect Controlled Substances in Patient Care Units," BioMed Research International, vol. 2017, 2017.

[26] P. Pierleoni, L. Pernini, A. Belli, and L. Palma, "An android-based heart monitoring system for the elderly and for patients with heart disease," International journal of telemedicine and applications, vol. 2014, p. 10, 2014.

[27] L. Neubeck, G. Coorey, D. Peiris, J. Mulley, E. Heeley, F. Hersch, et al., "Development of an integrated e-health tool for people with, or at high risk of, cardiovascular disease: The Consumer Navigation of Electronic Cardiovascular Tools (CONNECT) web application," International journal of medical informatics, vol. 96, pp. 2437, 2016.

[28] M. Al-Ramahi, Y. Chang, O. El-Gayar, and J. Liu, "Predicting Big Movers Based on Online Stock Forum Sentiment Analysis," 2015.

[29] Y. Yu, W. Duan, and Q. Cao, "The impact of social and conventional media on firm equity value: A sentiment analysis approach," Decision Support Systems, vol. 55, pp. 919-926, 2013.

[30] P. Phillips, S. Barnes, K. Zigan, and R. Schegg, "Understanding the impact of online reviews on hotel performance: an empirical analysis," Journal of Travel Research, p. $0047287516636481,2016$.

[31] Y. Guo, S. J. Barnes, and Q. Jia, "Mining meaning from online ratings and reviews: Tourist satisfaction analysis using latent dirichlet allocation," Tourism Management, vol. 59, pp. 467-483, 2017.

[32] Y. Jung, C. Hur, D. Jung, and M. Kim, "Identifying key hospital service quality factors in online health communities," Journal of medical Internet research, vol. 17, p. e90, 2015.

[33] Y. Xu, M. Armony, and A. Ghose, "The effect of online reviews on physician demand: A structural model of patient choice," 2016.

[34] M. A. Al-Ramahi, J. Liu, and O. F. El-Gayar, "Discovering Design Principles for Health Behavioral Change Support Systems: A Text Mining Approach," ACM Transactions on Management Information Systems (TMIS), vol. 8, 2017.

[35] M. Al-Ramahi, O. El-Gayar, and J. Liu, "Discovering Design Principles for Persuasive 
Systems: A Grounded Theory and Text Mining Approach," in System Sciences (HICSS), 2016 49th Hawaii International Conference on, 2016, pp. 3074-3083.

[36] R. Koppel and C. U. Lehmann, "Implications of an emerging EHR monoculture for hospitals and healthcare systems," Journal of the American Medical Informatics Association, pp. amiajnl2014-003023, 2014.

[37] E. Haddi, X. Liu, and Y. Shi, "The role of text pre-processing in sentiment analysis," Procedia Computer Science, vol. 17, pp. 26-32, 2013.

[38] D. M. Blei, A. Y. Ng, and M. I. Jordan, "Latent dirichlet allocation," the Journal of machine Learning research, vol. 3, pp. 993-1022, 2003.

[39] Y. Bao and A. Datta, "Simultaneously discovering and quantifying risk types from textual risk disclosures," Management Science, vol. 60, pp. 1371-1391, 2014.

[40] J. Thackara, "The design challenge of pervasive computing," Interactions, vol. 8, pp. 46-52, 2001. 